\title{
Effect of phosphorus level and inulin inclusion in a wheat based finisher pig diet on nitrogen, phosphorus and calcium metabolism and intestinal microflora
}

P. F. Varley, T. Sweeney, J. J. Callan, B. Flynn, C. McCarney, J. V. O'Doherty

University College Dublin, Dublin, Ireland

Email: patrick.varley@ucd.ie

Introduction The formulation of commercial grower finisher pig diets supplies excess dietary phosphorus (P) through the high inclusion levels of cereals which generally consist of indigestible $\mathrm{P}$ in the form of phytate $\mathrm{P}$. As a result incomplete digestion of $\mathrm{P}$ is largely responsible for unnecessary $\mathrm{P}$ excretion. Feeding reduced $\mathrm{P}$ diets supplemented with non digestible oligosaccharides (NDO) have been shown to promote mineral absorption in the large intestine of both humans and rats. Research data representative of NDO application in pigs are limited. Lopez et al. (2000) suggested that enhanced fermentation in the colon due to NDO feeding, such as inulin, apparently promotes better hydrolysis of phytate and, thus, enhanced colon P and calcium (Ca) absorption in small mammals. Inulin is classified as dietary fibre resistant to complete enzymatic degradation in the small intestine which is selectively fermented by Bifidobacteria and Lactobacilli spp. (Roberfroid et al., 1998). The objective of this experiment is to investigate the interaction between P and inulin level on mineral metabolism and intestinal microflora in a low and high $\mathrm{P}$ wheat based diet.

Materials and methods The experiment was designed as a $2 \times 2$ factorial comprising four dietary treatments. The experimental treatments were as follows: (1) $4 \mathrm{~g} / \mathrm{P} \mathrm{kg}$, (2) $4 \mathrm{~g} / \mathrm{P} \mathrm{kg}+20 \mathrm{~g} /$ inulin kg (3) $6 \mathrm{~g} / \mathrm{P} \mathrm{kg}$, (4) 6 g/P kg $+20 \mathrm{~g} /$ inulin $\mathrm{kg}$. The inulin used was a mixture of short and long-chain inulin (Synergy 1, Orafti). Sixteen finishing boars with a similar initial body-weight $(50.7 \mathrm{~kg}+4)$ were assigned to one of four dietary treatments $(\mathrm{n}=4)$. After a two week dietary adaption period pigs were transferred to metabolism crates for a 7 day apparent total tract nutrient digestibility study $(\mathrm{n}=4)$. Pigs remained on their respective diets until slaughter. Immediately post-slaughter, digesta samples (approximately $10 \mathrm{~g} \pm 1 \mathrm{~g}$ ) were aseptically recovered from the proximal colon in sterile conditions. Populations of Lactobacillus spp. and Bifidobacteria were selectively isolated and enumerated according to the method as described by previous authors (O'Connell et al., 2005). Typical colonies of each bacterium were counted, log transformed and presented per gram of digesta. Experimental data were analysed as a 2x2 factorial using the GLM procedure of the SAS Institute (1985). The statistical model investigated the main effects of dietary P concentration, inulin inclusion and the associated two-way interaction.

\section{Results}

There was no effect of Inulin or P level supplementation on P, Ca or N digestibility or proximal colon bacterial populations (Table 1).

Table 1

\begin{tabular}{|c|c|c|c|c|c|c|c|c|}
\hline \multirow[t]{2}{*}{ Treatment } & \multicolumn{2}{|c|}{ g P/kg } & \multicolumn{4}{|c|}{ Inulin } & \multicolumn{2}{|c|}{ 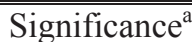 } \\
\hline & 4.0 & 6.0 & s.e. & no & yes & s.e. & $\mathrm{P}$ & Inulin \\
\hline \multicolumn{9}{|c|}{ Digestibility Coefficient } \\
\hline Dry matter & 0.903 & 0.901 & 0.005 & 0.899 & 0.905 & 0.005 & ns & ns \\
\hline Phosphorus & 0.569 & 0.546 & 0.015 & 0.542 & 0.572 & 0.014 & ns & ns \\
\hline Calcium & 0.649 & 0.563 & 0.029 & 0.590 & 0.622 & 0.028 & ns & ns \\
\hline Nitrogen & 0.871 & 0.886 & 0.013 & 0.868 & 0.889 & 0.012 & ns & $\mathrm{ns}$ \\
\hline \multicolumn{9}{|c|}{ Proximal Colon bacterial populations } \\
\hline Lactobacillus spp. & 7.330 & 7.372 & 0.188 & 7.429 & 7.273 & 0.188 & ns & ns \\
\hline Bifidobacteria. & 6.372 & 6.746 & 0.280 & 6.822 & 6.296 & 0.280 & ns & ns \\
\hline
\end{tabular}

${ }^{\mathrm{a}}$ : In the absence of an interaction main effects are presented.

Discussion and Conclusions In this experiment inulin was included at $2 \%$ which is in line with previous studies. The inclusion of inulin had no effect on $\mathrm{P}, \mathrm{Ca}$ or $\mathrm{N}$ digestibility in finisher pigs which is in agreement with Houdijk et al. (1999). There was no effect of inulin supplementation on proximal colon bacterial populations of bifidobacteria and lactobacilli spp. This was surprising because the main site of inulin fermentation has been previously reported to be in the colon where it promotes the growth of bacterial populations. However, Yasuda et al. (2007) demonstrated that $96 \%$ of inulin fed to growing pigs was degraded before reaching the proximal colon when included at $4 \%$, with the caecum displaying the highest inulin-degrading enzyme activity. In conclusion dietary inulin was probably totally degraded in the stomach and small intestine therefore diminishing any possible effect of inulin in the proximal colon of the finisher pig.

Acknowledgements Funding for this research was provided under the National Development Plan, through the Research Stimulus Fund, administered by the Department of Agriculture, Fisheries \& Food.

\section{References}

Houdijk, J.G., Bosch, M.W., Tamminga, S., Verstegen, M.W., Berenpas, E.B. and Knoop, H. 1999. Journal of Animal Science 77, 148-158.

Lopez, H.W., Coudray, C., Levrat-Verny, M.A., Feillet-Coudray, C., Demigné, C. and Rémésy, C. 2000. Journal of Nutritional Biochemistry 11, 500-508.

O'Connell, J.M., Sweeney, T., Callan, J.J. and O'Doherty, J.V. 2005. Animal Science 81, 357-364.

Roberfroid, M.B., Van Loo J.A.E. and Gibson G.R. 1998. Journal of Nutrition 128, 11-19.

Statistical Analysis Systems Institute 1985. Statistical analysis systems. 6.12 ed. SAS Institute Inc., Cary, NC, USA

Yasuda, K., Maiorano, R., Welch, R.M., Miller, D.D. and Lei, X.G. 2007. Journal of Nutrition 137, 2399-2404. 